\title{
Discussion on the impact of Chinese traditional culture on tourism management
}

\author{
Xiaofei Huang \\ Chengdu Polytechnic, Chengdu Sichuan, 614000, China
}

Keywords: Chinese traditional culture, Tourism management, Impact, Development trend.

\begin{abstract}
. tourism management as an important discipline in modern management field plays a critical role in tourism industry. Chinese traditional culture is closely related with tourism management, so reasonable application of Chinese traditional culture can correctly guide tourism management to further improve the quality of tourism management. This article through starting from the tourism concepts properly analyzes the impact of Chinese traditional culture on tourism management, and proposes countermeasures for actively carrying out tourism management in modern time with the hope to truly promote better development of tourism management industry and to make contributions for Chinese social progress.
\end{abstract}

\section{Introduction}

In recent years, Chinese tourism management industry has experienced long time development and achieved new development results in new times. Analysis from the current occupancy volume of Chinese tourism resources, China has rich cultural and natural tourism resources. In the long time development process, accumulation of Chinese traditional culture has created new development direction of tourism industry. The integration of natural and cultural resources has promoted Chinese tourism industry to form a new development trend. How to apply the force of Chinese traditional culture to help tourism management industry to obtain new development chances and take up advantageous development position in world tourism industry has become an issue attracting social attention. Thus, this article makes analysis on the development of tourism management industry from Chinese traditional culture, which is of great value.

\section{Tourism concept contained in Chinese traditional culture}

China is one of most important countries with ancient civilization and extensive and profound traditional culture impacting the development of different fields in modern China and even the world cultural progress. Chinese traditional culture has formed its unique cultural connotation in the long-time development process and created characteristic cultures. This is playing critical role in promoting the development of Chinese traditional culture. In Chinese traditional concepts, the most influential are Confucius, and Buddhism. It is based on these three traditional cultural thoughts, Chinese tourism culture can form its unique cultural connotation in the long time development and present unique development character under the influence of different local regional culture. It has even become the basic clue for guiding the progress of Chinese tourism culture brining new vitality and energy for Chinese modern tourism culture. Thus in new time, Chinese tourism management department should intensify the focus on traditional culture in specific management procedures and pay attention to take measures to penetrate traditional cultural thoughts in tourism management work so as to promote the improvement of tourism managing work and provide relevant support for modern construction and development of tourism management industry.

\section{Impact of Chinese traditional culture on tourism management work}

China has extensive and profound culture. It has brought important impact on the development of Chinese tourism management industry and to some degree it has promoted the progress of tourism 
management work and gave correct guidance to its development. Next the article will make analysis on the impact of Chinese traditional culture on tourism management work.

\section{Impact of people-oriented management concept}

People-oriented management concept is an important ideology in Chinese traditional culture which has brought about significant impact on different fields in the long time process of inheritance and development. For tourism management work, penetrating people-oriented management concept into tourism management work can help focus on people so as to present some people-based thought. Consumers can be as the core to carry out various management work. Make optimization and adjustment according to consumer's demand. In this way, employees' work activity and positivity can be significantly improved and tourism management work can be widely accepted by consumers so that tourism management work can obtain better development in the new time.

\section{Impact of management concept of "harmony is precious"}

The ideology of "harmony is precious", originated from Chinese Confucianism, is an important management concept as well as a common ideological concept for all Chinese ${ }^{[1]}$. Penetrating this management concept into management work during tourism management can help enterprise employees intensify their sense of identity and belongingness for the tourism enterprise so as to gradually improve the internal cohesion to provide condition for enterprise to get competitive advantage in market. Meanwhile, under the influence of this ideology, enterprise management will not give compulsory restriction to employees with rigid regulations and clauses but to use the guidance of thoughts and intensification of awareness to guarantee that employees can actively cooperate with managers' work so as to improve the enterprise management efficiency and effect and lay solid foundation for sustainable and healthy development of tourism management work.

\section{Impact of the personality charm of winning people by virtue}

In Chinese traditional culture development process of thousands of years, Confucianism calls for the country to insist on ruling the country by virtue, which is also applicable for other management. The application of moral governing ideology into tourism management work is to play the personal quality of leadership to help enterprise employees conscientiously accept and participate into enterprise various management work under the influence of concept of winning people by virtue so as to promote the continuous improvement of enterprise management level. Only by penetrating the virtue into tourism enterprise management work can employees have trust on enterprise leadership so as to conscientiously support various management work and guarantee the smooth progress of enterprise tourism management work.

The impact from Chinese traditional culture on tourism management work shows in three aspects. Tourism management staffs should pay attention to further exploration on Chinese traditional culture about those parts which can suits with Chinese traditional culture if they want to further improve the management quality and level so as to use the force of Chinese traditional culture to correctly guide tourism enterprise management work so that enterprise management work can be accepted by employees and the mass consumers for the purpose of providing conditions for obtaining competitive edge in the modernization construction and Chinese tourism industry in world competition in the new time.

\section{Specific measurements to integrate Chinese traditional culture into tourism management work}

It can be seen from the impact of Chinese traditional culture on tourism management that, for better development of Chinese tourism industry, China should try to properly integrate Chinese traditional culture into tourism management work for correct guidance of tourism management work. Specifically, it can be started from below aspects: 


\section{Use traditional culture for scientific integration planning of the tourism culture in tourism areas}

When properly integrating issues of Chinese traditional culture into tourism management work, the important point is to use Chinese traditional ideological connotation for scientific integration and planning for characteristic tourism cultural resources in travelling areas so as to make sure advantages of tourism cultural resources in different regions can be fully used on the basis on fully referring to excellent traditional culture so as to improve the superiority of tourism culture in this area and to provide conditions for the development of tourism industry in this area ${ }^{[2]}$. Specifically, during developing current tourism cultural resources, tourism administrative department should use Chinese traditional cultural concept for organic integration between traditional culture and modern tourism culture so as to use the integrative advantages of two cultures to make correct guidance for tourism management work to realize the fully exploration of cultural resources in travelling areas. Only in this way can cultural resource advantages in travelling areas be fully improved to lay solid foundation of sustainable and steady development of regional tourism work.

\section{Consummate the tourism cultural construction groundwork to promote cultural promotion}

When properly integrating issues of Chinese traditional culture into tourism management work, the basic precondition is to consummate the cultural basic work so as to integrate traditional culture with modern tourism management work. During the process of intensifying tourism management work, conduct relevant cultural promotion and education work, conduct Chinese traditional culture universal education to the society so as to help the public to form deep understanding of the values and functions of tourism management work through understanding and knowing traditional culture so that when participating relevant travelling activities they can actively cooperate the tourism management behaviors in the travelling areas and to provide conditions for the optimized implementation of tourism management work. Only in this way, Chinese tourism management work can be fully and comprehensively improved and tourism industry can obtain better development in the new time.

\section{Fully excavate cultural connotation and expand the product depth}

In new time, to truly integrate traditional cultural ideology into modern tourism management work, relevant cultural inheritance workers and tourism management staffs should actively pay attention to the excavation of the connotation of traditional culture so as to extract the cultural essence in tourism management work and pay attention to penetrate the ideological connotation of traditional culture into the development work of tourism management products so as to further expand the product $\operatorname{depth}^{[3]}$. In this way, tourism management work in different areas can form characteristic cultural connotation with the support of traditional culture and attract consumers with unique charms to provide solid guarantee for the sustainable and steady development of regional tourism industry in modern society.

\section{Improve the quality of multi-level cross -cooperation work and enrich tourism cultural form}

Under current social background, to win victory in global competition and obtain sustainable development, Chinese tourism industry cannot limit tourism pattern within sightseeing tour during developing tourism industry but to use the fusion between traditional culture and tourism culture to explore richer and specific tourism cultural form to make contribution for constructing tourism culture with Chinese characteristics ${ }^{[4]}$. Only in this way can Chinese tourism culture satisfy Chinese consumers' demand and lay human resource foundation to the development of Chinese tourism industry. Meanwhile, only enriching tourism cultural form can China can develop cultural tourism on the basis of sightseeing tour so as to improve the attractiveness of Chinese tourism sites for the world people and to provide conditions for the persistent development of tourism industry. 


\section{Development trend of Chinese modern tourism culture under the influence of traditional culture}

With the progress and development of modern society, under the attack of economic globalization and cultural diversified concepts, Chinese tourism culture is presenting new development trend in continuous conflicts and integration. This has brought about certain impact on the steady operation of Chinese tourism industry. Thus, on the basis of reasonably integrating traditional culture into tourism management work, make proper analysis on the development trend of current tourism culture to make correct guidance for the modernization construction of tourism industry.

Firstly, the applicable development trend of tourism culture is intensifying gradually. Chinse tourism culture has presented thick fundamentality characteristic in the form. Make analysis on the research purpose of relevant researchers and the roles of traditional culture on tourism management, it can be seen that it has strong applicability and practicableness. Also, it has produced positive impact on the sustainable development of tourism industry in the process of practical application. The influence has been thought highly of by the tourism management staffs so that this trend will be inevitably intensified in the future.

Secondly, the trend of magnification of tourism management work. Seeing from current tourism culture and the development situation of tourism management work, in future society, tourism culture will extend into broader field with tourism work contents expanded also. In this way, Chinese tourism management industry will embrace new development chance and tourism management industry will develop gradually

In addition, the trend of scientific development of tourism management. With the progress of modern social science and technology, penetrate tourism cultural concept in tourism management work, pay more attention to the application of modern information technology, and complete the analysis and integration of tourism culture through information technology so as to help the tourism culture to produce more important influence on tourism management. Gradually solve various problems in tourism management work to intensify the scientific trend of tourism management work [5].

At last, tourism management disciplinary tendency. Under the influence of traditional culture, Chinese traditional culture has stepped into academic center from academic outer sphere. Its position in disciplinary study field has been consolidated and intensified with tourism culture and management disciplinary system developed and perfected. It can be seen that, under current social background, Chinese tourism culture and disciplinary tendency of tourism management will be inevitably intensified to a certain degree to lay a solid foundation for the development of tourism management industry.

\section{Conclusion}

To sum up, China has extensive and profound traditional culture with a long history. There exist unique cultural essence in long time development process. This has brought significant influence on Chinese tourism management work. Therefore, in the new era, for better development of tourism management work, truly promoting the progress of tourism management industry and helping Chinese tourism industry to win in world competition, it is very necessary to explore measurements of application of traditional culture into tourism management work and to use the force of traditional culture to improve the level of Chinese tourism management work for providing relevant support for the sustainable and steady development of tourism so that Chinese tourism can get wide recognition under current social background and provide solid guarantee for the international development and modernization construction of tourism industry. 


\section{References}

[1] Yu Yingying. Analysis on the impact of Chinese traditional culture on tourism management under the new situation, Journal of Chifeng University (natural science edition),2015(17):125-126.

[2] Han Rui. Analysis on the impact of Chinese traditional culture on tourism management, Heilongjiang Science, 2016,7(8):146-147.

[3] Wang Zhe. Analyzing the influence of Chinese traditional culture on tourism management, Modern Communication, 2013(11):133-133.

[4] He Yougui. Discussion on the influence of Chinese traditional culture on tourism management, New Economy, 2013(17):65-66.

[5] Peng Rong. Analysis on the impact of Chinese traditional culture on tourism management, Human Resource Management, 2014(6):307-307. 